\title{
Editorial
}

\section{Pesquisa e produção científica}

A pesquisa e a produção científica são os meios que embasam o conhecimento que é aplicado na prática médica. A pesquisa pode ser iniciada já na formação acadêmica do aluno de Medicina, trazendo senso crítico, técnicas de laboratório, habilidades na pesquisa bibliográfica e maturidade profissional. A produção científica tem grande importância na divulgação de resultados e respostas de hipóteses, propagando o conhecimento para outros profissionais por meio da publicação em periódicos, jornais e revistas.

Em 2018, ocorreu o XXXVII Congresso Médico Universitário (COMU), principal evento do Departamento Científico (DC) da Faculdade de Medicina da USP que preza pela excelência na formação médica e no incentivo à pesquisa científica, com a participação de profissionais renomados em palestras, workshops e avaliação de trabalhos científicos. Nesta edição, contamos com 1378 congressistas inscritos e 53 trabalhos científicos submetidos por acadêmicos de diferentes faculdades de medicina do Brasil, dos quais 18 foram premiados.

Em meio a este cenário, é inevitável não trazer um desafio que o país deve superar: a falta de incentivo à pesquisa e à produção científica. O corte orçamentário destinado à Pesquisa sofrido em 2018 está refletindo na falta de financiamento de diversas linhas de pesquisas de inúmeras áreas, levando ao consequente abandono e desestímulo aos acadêmicos a participarem de Iniciação Científica.

Apesar desta realidade, o COMU mantém-se seguro de seu propósito, com o apoio, auxílio e orientação de docentes ao fomento à pesquisa de qualidade e o reconhecimento do trabalho de acadêmicos, que investem o seu escasso tempo para leitura, interpretação e experimentação. Como fruto de tanto esforço, os artigos publicados nesta edição deixam claro motivos pelos quais não se deve haver corte orçamentário à Pesquisa: a importância dos resultados embasa um conhecimento que deve ser divulgado, o impacto positivo que a iniciação científica traz para a formação acadêmica e o crescimento profissional de toda a equipe envolvida na pesquisa.

Desejo a todos uma boa leitura e que mantenham-se sempre dedicados à produção de conhecimento!

Guilherme Tetsuo Yokoy Numakura Acadêmico de Medicina da FMUSP Ex-presidente do Departamento Científico (2018) Presidente dos Prêmios Científicos do XXXVII COMU - 2018 e-mail: guilherme.numakura@fm.usp.br 